\title{
Strategic planning of construction and reconstruction of the facilities of the heat supply systems with the use of scenario approach
}

\author{
Natalia Verstina $^{1 *}$, Evgeny Evseev ${ }^{2}$, Olga Tsuverkalova ${ }^{3}$ \\ ${ }^{1}$ Moscow State University of Civil Engineering, Yaroslavskoe shosse, 26, Moscow, 129337, Russia \\ ${ }^{2}$ Moscow Institute of Physics and Technology, Kerchenskaya st., 1 “A”, Moscow, 117303, Russia \\ ${ }^{3}$ Volgodonsk Technical Institute, the Branch of National Research Nuclear University, Lenin st., 73/94, \\ Volgodonsk, 347360, Russia
}

\begin{abstract}
Some topical issues of strategic planning of construction and reconstruction of heat supply systems are considered in the article, taking into account the features of its organization in the certain territories of our country with different climatic, economic, city-planning and social conditions. The article presents the results of the analysis of the strategic documents of the heat supply development in various countries, which showed the need of formation of management instruments, providing the possibility of planning of specific scenarios of the heat supply development in the territories of our country. The key conditions of strategic planning, are revealed. They include providing the solution of social and environmental problems as well as the matters of energy security of consumers, which are in the centre of global environmental challenges now. The legislative arrangements and the experience of the use of "Heat Supply Schemes" in the territories of the Russian Federation are chosen as the materials. The scenario approach with the use of the method of the hierarchy analysis is considered to be the basis for planning of construction and reconstruction of the facilities of the heat supply systems. According to the scientific approach, chosen in the research, the level hierarchy of the strategic planning process is offered. The major factors, influencing the development of heat supply of territories are analysed, the main factors and their purposes, as well as the basic scenarios of the development, are described. The authors offer four scenarios for the choice of options for construction and reconstruction of the facilities of heat supply systems, taking into account the practice of its organization in various countries. The importance of the basic scenarios for the strategic development of the heat supply system in the territory is estimated according to the hierarchy levels on the basis of the method of paired comparisons with the subsequent aggregation of the received results. The approbation of the offered management instrument on the example of the urban area allow to prove the scenario of the decentralized heat supply of the explored territory as the most perspective scheme as well as to raise the questions of possible expansion of the offered management instrument.
\end{abstract}

\footnotetext{
*Corresponding author: verstina@mail.ru
} 


\section{Introduction}

Successful functioning of subjects of economic activity in the country in the conditions of market economy has to rely not only on the solution of the current tasks, but also on drawing up the long-term strategic plans, connected with successful overcoming global world challenges. Organization of activity of subjects of the heat supply industry plays a rather essential role in many countries' economy, from consumers of heat energy to its producers. As numerous researches prove, the improvement of strategic planning of the development of the industry of heat supply, from the national level, to the level of municipalities, has direct impact on the increase in level of social-and-economic development of the country and its energy security. The facilities of heating systems represented by the industrial generating capacities and local sources of energy resources, the high-level and local heating systems, structures of input of heat energy to its consumers, are the integral and considerable part of the infrastructure of all modern cities which construction and reconstruction have to be harmonized with their development.

Considerable variety is the distinctive feature of construction and reconstruction of facilities of heat supply systems. Just few enough countries in the world are characterized by the uniform approach to the organization of the heat supply development with the corresponding tasks of design and construction of these facilities, important for country' economy. The research completed by the authors proved $\mathrm{n}$ the wide range of solutions, from centralization of heat supply of the cities and the use of large sources of cogeneration covering considerable territories of building development, to sone individual decisions of the organization of heat supply of real estate with the local power sources, which are mainly focused on electricity. In modern conditions the construction of renewable energy resources that significantly changes the settled strategic reference points of development planning of the cities is considered to be one of the global challenges of development of economy and society in the sphere of heat power system. In this regard the development of instruments of management, which allow the public authorities of various levels and subjects of economic activity to implement systemic approach to the matters of planning of construction and reconstruction of the facilities of heat supply of the real estate, considering this mater in a complex in scales of certain territories of building development of the country, become relevant..

\section{Materials}

The analysis, carried out by authors, proved that the instruments of strategic management of documents in the considered area are developed in various degree in the different countries. At the same time practically, all the countries are focused on providing the weighed longterm decisions concerning providing real estate objects with heat energy. The state policy in the field of development of the power sphere of the country is fixed at the national level of the country most often, for example: The Energy Strategy till 2035" in Russia, Strategy of competitive, steady and safe power industry of the EU till 2028, Power and Climatic Concept for 2020-2030, White book of Power Industry of Australia (2015) [1, 2, 3]. The postulation of the principles and purposes of development which defines the requirements to the instruments of management, supporting the implementation of the policy, pursued by the state is important for strategic planning. At the same time the substantial content of the documents of this level regarding the declaration of the priorities which can be used when developing the instruments of management differs very much. The reliability of power supply and its security, energy efficiency and profitability, ecological safety belong to the matters considered most often. The authors suppose, that all this, discussed in complex also represents, makes up the basis for forming of factors of strategic development in any country 
during making decision concerning the configuration of strategic alternatives when planning construction and reconstruction of the facilities of heat supply systems.

According to the Federal law No. 172-FZ "On strategic planning in the Russian Federation" (approved 28.06.2014) strategic planning is performed at all the levels and is aimed at the sustainable development both the country in general, and its separate subjects and municipal units, branches of economy and other economic agents [4]. This law is unique and interesting for the research, as it allows to harmonize the plans for the development of heat supply of the territories with planning of construction and reconstruction of the facilities of heat supply systems in strategic prospect, setting uniform rules of the organization of strategic management processes. The authors pointed out some elements of strategic planning provided legislatively, which create the basis for forming of management instruments at various levels, from the level of the state, to the level of municipalities (Table \#1).

Table 1. Elements of strategic planning considered when developing management instruments

\begin{tabular}{|l|l|}
\hline \multicolumn{1}{|c|}{$\begin{array}{c}\text { Elements of } \\
\text { strategic planning }\end{array}$} & \multicolumn{1}{c|}{ Contents } \\
\hline Goal-setting & $\begin{array}{l}\text { Determination of the directions, purposes and priorities of social-and- } \\
\text { economic development }\end{array}$ \\
\hline Forecasting & $\begin{array}{l}\text { Determination of the directions, risks, results of social-and-economic } \\
\text { development }\end{array}$ \\
\hline Planning & $\begin{array}{l}\text { Development and implementation of the plans of different level aimed at the } \\
\text { to achievement of the goals of social-and-economic development }\end{array}$ \\
\hline Programming & $\begin{array}{l}\text { Development and implementation of the state and municipal programmes } \\
\text { aimed at the achievement of the goals of social-and-economic development }\end{array}$ \\
\hline
\end{tabular}

The research completed proved that the last two elements provided in Table \#1 are the weakest link in practice of strategic management by construction and reconstruction of the facilities of heat supply systems in many countries. In particular, the author of the publication devoted to the comparative analysis of the organization of strategic planning in various countries (from the countries of the European continent (the Russian Federation, the European Union countries) to the leading countries of other continents (Japan, the USA, Australia) noted the availability of rather strong dispersion of elements of strategic planning even when comparing the main documents of strategic planning of development of the power sphere of economy [5]. In this regard the materials from the Russian management practice by development of heat supply of the real estate facilities were taken for the research with interrelations with data on construction and reconstruction of the facilities of heat supply systems at the level of territories of the municipalities representing the most representative base of materials on the studied perspective.

At the same time, it is also necessary to consider the branch and regional features during its implementation, despite the availability of the general elements inherent in strategic planning of the development of economy in all countries. According to the specialists of the International Energy Agency (IEA), "the combination of power planning to business planning of the heat-supplying organizations" is the feature of the heat supply development [6]. Such planning is focused not only on the increase in the efficiency of functioning of the heat-supplying organizations, but also on providing the solution of social and environmental problems as well as on the matters of energy security of the consumers, which remain in the center of global environmental challenges now.

One of the main documents of strategic planning, considered by the authors at the country meso-level, defining the needs for construction and reconstruction of the facilities of the heat supply systems in the Russian Federation are "Requirements to the heat supply schemes " [710]. This document states, that the development of the heat supply schemes in territories is performed "for the purpose of meeting the demand for heat energy (power) and the heat carrier, providing reliable heat supply with the most economic method at the minimum harmful effects on the environment as well as the economic incentives of the heat supply 
systems development and introduction of energy-saving technologies". It is complex in nature and acts as the concentrated representation of what decisions on the organization of heat supply are to be focused on the irrespective of the fact which type of heat supply (centralized or local) prevails in the country. The developed schemes have to contain the description of the current situation which has developed in the sphere of production, transfer and consumption of heat energy for the purposes of heat supply, as well as determination of the perspective directions of its development, the list of the planned actions and justification of their expediency proceeding from the aforesaid criteria. One of the studied materials of the obligatory sections ("Schemes of Heat Supply") considered among the materials is "Master development plan for the heat supply systems of the settlement, city district, federal city" which has to contain the description of not less than two options of perspective development of heat supply system as well as the justification of the choice of priority option (according to item 59 of the "Requirements").

The system approach on the basis of the method of the hierarchy analysis provided by $\mathrm{T}$. Saati and K. Kearns in work [9] was chosen as the theoretical-and-methodological base. The authors consider two types of planning: direct and reverse planning. The factors influencing the development of the system are analyzed, potential impacts on the system are defined and the probabilities of possible outcomes are estimated within the direct planning, relying on the current state of the system. The process of the reverse planning proceeds from the desirable result and consists in the determination of measures for its achievement. The best result is achieved by the iterative application of processes of direct and reverse planning; that allows to reach the best compromise between the desirable and possible scenarios of the development.

\section{Results}

According to the scientific approach, chosen in research, the hierarchy of the studied strategic planning process is considered on the following levels [11]:

1) planning purpose;

2) factors having impact on the achievement of resulting effect;

3) stakeholders (actors), whose priorities have to be considered when making decisions, having opportunity to influence the factors directly or indirectly;

4) purposes (priorities) of the actors;

5) politicians whom the actors follow for the achievement of the purposes (optional level);

6) possible scenarios (basic);

7) final combined scenario.

These levels were concretized in relation to the development of the facilities of the heat supply systems in the territories, supposing their construction and reconstruction.

The ultimate goal of strategic planning, e.i. the development of the heat supply system of the municipal unit, taking into account the requirements defined earlier, is at the top level. The main studied factors include: economic, technology, social and ecological factors. Their contents and influence on the activity of the heat-supplying organizations, which are the most interested in planning, have been considered in the research [12] in detail. In addition, developing the method of forming of factorial space, offered in the work, the authors offer to include the city-planning factors in the list of significant factors, as the development of the scheme of heat supply has to be performed taking into account the existing city-planning plan and perspective building. Climatic factors, despite their importance, are not considered in this work as the actors cannot make any impact on them. However, their influence can be considered indirectly, through the other factors assessment. If necessary, this list can be expanded or detailed. 
The main actors, whose purposes and interests are to be taken into account when developing and updating the schemes of heat supply are described in work [13] rather in detail. The authors of this research refer to the consumers of heat energy (with the subsequent possible specification, e.i. the population, the industry, other consumers), heat-supplying organizations, authorities, suppliers of other types of resources (water, gas, etc.) as some of them. It is offered to add this list and to include environmental public organizations and movements taking into account strengthening of the trends aimed at the ecologization of the economy of all the countries. This list can be expanded. The purposes of actors were systematized and presented in the aggregated form in Figure 1 for carrying out the research.

There are scenarios of the heat supply development which have been created on the basis of method of systematization and synthesis of regulating documents and practice of the organization of heat supply in different countries [11-13]. The application of this method allowed to allocate four types of basic scenarios of universal character which use invariant to the nature of building of territories and their country dislocation $[14,15]$ :

1) Centralization (C). Nowadays the centralized heat supply is dominating in the majority of the cities in the Russian Federation, in the most part of China, in the countries of the former Soviet Union, some Scandinavian European countries. This scenario provides further expansion of systems of the centralized heat supply from the positions of strategic planning, taking into account the increase in the quantity of consumers of heat energy and perspective plans of the settlement development.

2) Decentralization (D). Despite the historically developed preference of centralized systems of heat supply in the Russian Federation, the steady tendency to the transition to the boiler houses of low power and individual sources of heat supply characteristic of many countries of the world (including developed economic systems, such as the USA, Canada, Japan) was outlined in the recent years. That is caused by greater flexibility of such systems.

3) Electrical heat supply (E). This scenario provides the transition from the traditional systems of heat supply to the systems using transformation of electrical energy to heating. Two options are possible: the direct use of electrical heating devices or the use of electric boilers for heating of the heat carrier. The benefits of electric heating include big environmental friendliness in comparison, the disadvantage is a rather high cost. It found the application in various territories of such countries as Norway (70\%), the Canadian province of Quebec (more than 60\%), France, etc. Nowadays the use of systems of electric heating is advisable in the territories of the countries with the short heating period.

4) Alternative sources (A). The use of nontraditional and renewable sources belongs to this scenario: solar energy (Cyprus, Israel), geothermal sources (Iceland), biofuels, etc. Today the given scenario has not gained considerable distribution even in the developed countries of the world, however in the conditions of ecologization it can be considered as one of the possible, providing achievements of the whole complex development priorities which are put by modern society in front of engineering life support systems of real estate facilities.

Thus, the problem of planning of the strategic development of the heat supply system of the certain territory at the level of municipality of the country can be presented in the form of the following hierarchy (Figure 1):

The main objective of strategic planning is the determination of specific weight of basic scenarios in the combined scenario assuming certain decisions on construction and reconstruction of the facilities of heat supply systems and considering the features of situation of planning in the considered territory [13-16].

The procedure of the choice of the combined scenario developed in this research and making the maintenance of the offered instrument of management is performed step by step with the use of method of paired comparisons at each level of the hierarchy and includes the following stages: 
1. For the description of each basic scenario the matrix, with is used to estimate their influence on the main indicators of achievement of the goals of actors, is formed.

2. At the next stage the assessment of the impact of the allocated groups of factors on the ultimate goal of planning (the development of the heat supply system) is carried out [5].

3. Then the influence of actors on each of the allocated factors is estimated; that demands the creation of set of matrixes of paired comparisons. The received vectors of priorities form the influence matrix. Multiplication of the received matrix on the vector of priorities gives us the influence of actors on the whole set of factors.

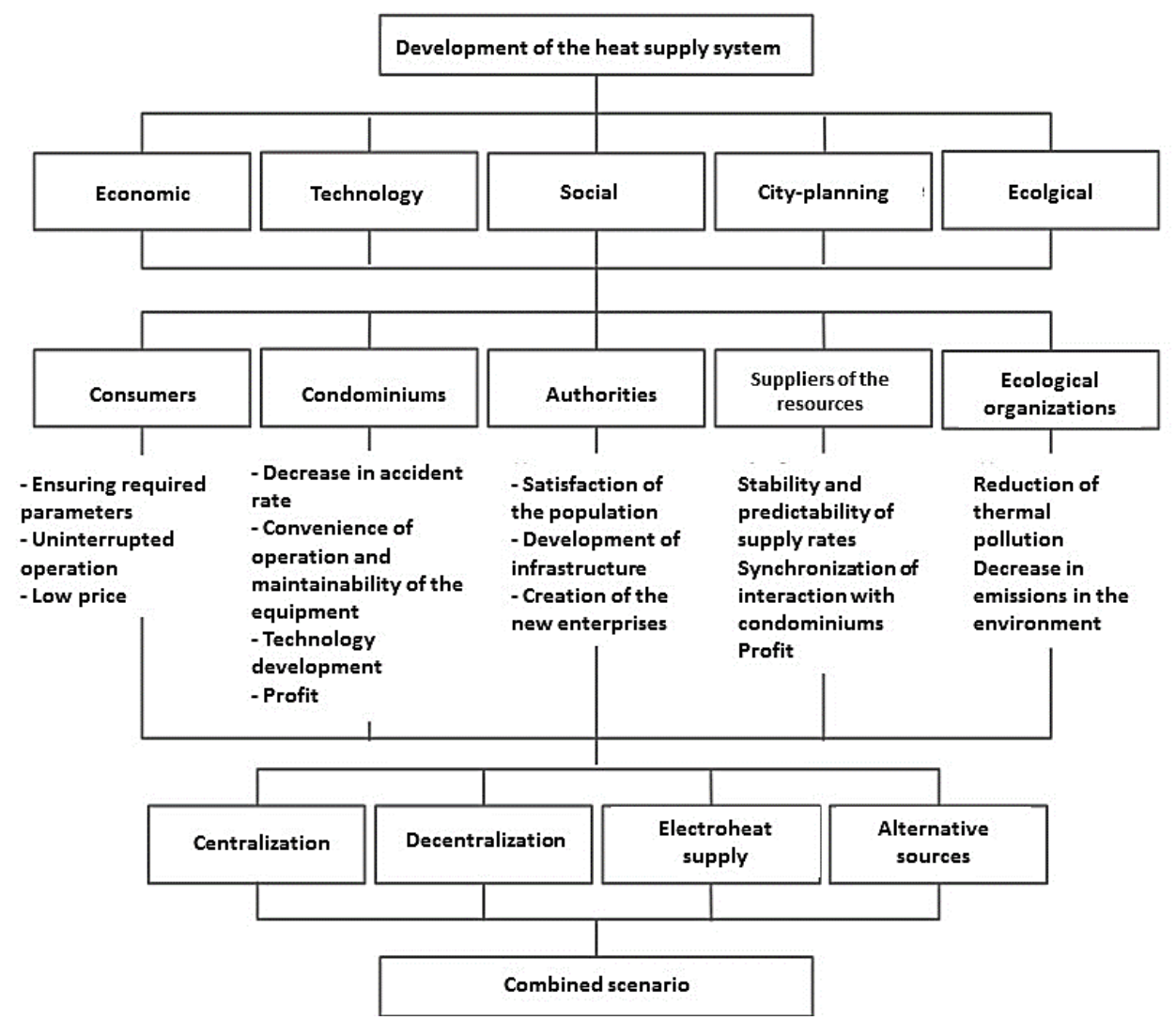

Fig. 1. Hierarchy of the development of the heat supply system planning

4. For each of the considered actors we define the vectors of priorities [17], concerning the indicators of achievement of their purposes. Multiplying the received vector on the weight of the corresponding actors, we receive the importance of the purposes for the development of the heat supply system. Choosing the indicators, most significant for each of the actors, we unite them in the summary vector of the purposes which will reflect the importance of the purposes of actors when choosing scenarios of the development.

5. The final stage of research consists in the assessment of basic scenarios of the chosen purposes [18-20]. The weight of scenarios concerning each of effective objectives are defined on the basis of matrixes of paired comparisons. The result of this procedure is the summary "scenarios purposes" matrix. Multiplying it on the vector of the purposes received earlier, we can find the total weight of the basic scenarios in the combined scenario. The more is the weight of the basic scenario the more is the share of appropriate technologies in the development of the heat supply system. 


\section{Discussion}

We consider the use of the offered management instrument on the example of Volgodonsk, which is located in the southern part of the Russian Federation. It was used by municipality when updating "The Scheme of Heat Supply" of this territory. Considering the lack of alternative energy sources in this territory, we will consider just three of four basic scenarios. We will create the table of the assessment of the impact of basic scenarios on the purpose of actors (Table \#2).

Table 2. Assessment of the impact of basic scenarios on the purposes of actors.

\begin{tabular}{|c|c|c|c|}
\hline \multirow[t]{2}{*}{ Actors and indicators of their purposes } & \multicolumn{3}{|c|}{ Basic Scenarious } \\
\hline & $\mathrm{C}$ & $\mathrm{D}$ & $\mathrm{E}$ \\
\hline \multicolumn{4}{|l|}{ Consumers } \\
\hline Uninterrupted operation of heat supply & 0 & +1 & -1 \\
\hline Low price & -1 & +2 & -2 \\
\hline Compliance of heat supply to the required parameters & 0 & +2 & +2 \\
\hline \multicolumn{4}{|l|}{ Condominiums } \\
\hline Profit & +2 & -1 & -2 \\
\hline Decrease in the accident rate & 0 & +1 & -1 \\
\hline Convenience of operation and maintainability of the equipment & 0 & +2 & -1 \\
\hline Technology development & +2 & +1 & -1 \\
\hline \multicolumn{4}{|l|}{ Authorities } \\
\hline Level of satisfaction of the population & 0 & +3 & -1 \\
\hline Development of infrastructure & +1 & +3 & +3 \\
\hline Creation of new enterprises & 0 & +2 & +1 \\
\hline \multicolumn{4}{|l|}{ Suppliers of resources } \\
\hline Stability and predictability of supply rates & +2 & -1 & -2 \\
\hline Synchronization of interaction with condominiums & +2 & -2 & -2 \\
\hline Profit & +1 & -1 & -2 \\
\hline \multicolumn{4}{|l|}{ Environmental organizations } \\
\hline Reduction of heat pollution & -1 & +1 & +1 \\
\hline Decrease in the emissions in the environment & -1 & +1 & +3 \\
\hline
\end{tabular}

Having formed the matrix of paired comparisons, we will carry out the assessment of the impact of groups of factors on the development of the heat supply system (Table \#3).

Table 3. Determination of the importance of groups of factors on the development of the heat supply system of the territory

\begin{tabular}{|l|l|l|l|l|l|l|}
\hline Groups of factors & F1 & F2 & F3 & F4 & F5 & Priorities vector \\
\hline F1. Economic & 1 & 1 & 5 & 3 & 5 & 0.360 \\
\hline F2. Technology & 1 & 1 & 5 & 3 & 5 & 0.360 \\
\hline F3. Social & $1 / 5$ & $1 / 5$ & 1 & $1 / 3$ & 1 & 0.064 \\
\hline F4. City-planning & $1 / 3$ & $1 / 3$ & 3 & 1 & 3 & 0.152 \\
\hline F5. Ecological & $1 / 5$ & $1 / 5$ & 1 & $1 / 3$ & 1 & 0.064 \\
\hline
\end{tabular}

The calculation results prove that the most significant factors for the strategy of development of the heat supply system in Volgodonsk are economic and technology factors.

The results of comparisons and vectors of priorities for the group of economic factors are given in Table \#4. 
Table 4. Determination of the extent of influence of actors on the economic factors

\begin{tabular}{|l|c|c|c|c|c|c|}
\hline Actors & $A 1$ & $A 2$ & $A 3$ & $A 4$ & $A 5$ & Priorities vector \\
\hline A1. Consumers & 1 & $1 / 7$ & $1 / 7$ & $1 / 5$ & 5 & 0.060 \\
\hline A2. Condominiums & 7 & 1 & 1 & 3 & 9 & 0.371 \\
\hline A3. Authorities & 7 & 1 & 1 & 3 & 9 & 0.371 \\
\hline A4. Suppliers of resources & 5 & $1 / 3$ & $1 / 3$ & 1 & 7 & 0.171 \\
\hline A5. Environmental organizations & $1 / 5$ & $1 / 9$ & $1 / 9$ & $1 / 7$ & 1 & 0.027 \\
\hline
\end{tabular}

We also build the matrixes for other groups of factors. We receive the following priorities vector:

- for technology factors $\left(\begin{array}{lllll}0.216 & 0.575 & 0.059 & 0.113 & 0.038\end{array}\right)^{\mathrm{T}}$;

- for social factors $\left(\begin{array}{llllll}0.374 & 0.074 & 0.374 & 0.038 & 0.140\end{array}\right)^{\mathrm{T}}$;

- for city-planning factors $\left(\begin{array}{lllll}0.309 & 0.108 & 0.513 & 0.035 & 0.035\end{array}\right)^{\mathrm{T}}$;

- for ecological factors $\left(\begin{array}{lllll}0.242 & 0.518 & 0.099 & 0.028 & 0.113\end{array}\right)^{\mathrm{T}}$.

Uniting the found vectors, we receive the matrix of the actors' influence on the considered factors. Multiplying the received matrix on the priorities vectors, we estimate the influence of certain actors on the set of factors:

$\left(\begin{array}{lllll}0.060 & 0.216 & 0.374 & 0.309 & 0.242 \\ 0.371 & 0.575 & 0.074 & 0.108 & 0.518 \\ 0.371 & 0.059 & 0.374 & 0.513 & 0.099 \\ 0.171 & 0.113 & 0.038 & 0.035 & 0.028 \\ 0.027 & 0.038 & 0.140 & 0.035 & 0.113\end{array}\right) \times\left(\begin{array}{l}0.360 \\ 0.360 \\ 0.064 \\ 0.152 \\ 0.064\end{array}\right)=\left(\begin{array}{l}0.186 \\ 0.395 \\ 0.263 \\ 0.112 \\ 0.044\end{array}\right)$.

The further research assumed the development in two ways: it is still possible to consider all the actors, or to choose the most significant actors, whose cumulative influence on factors is prevailing. The most significant actors in our case are the consumers, heat-supplying organizations and authorities. Their cumulative influence on the factors defining the development of the heat supply system is $0.186+0.395+0.263=0.844(84.4 \%)$. Therefore, we will just consider only these actors. Priorities vectors for the chosen actors were defined. For consumers the calculation is given in Table \#5.

Table 5. Determination of the purposes importance for consumers

\begin{tabular}{|l|c|c|c|c|}
\hline & P1 & P2 & P3 & Priorities vector \\
\hline P1. Compliance to parameters & 1 & $1 / 5$ & $1 / 3$ & 0.109 \\
\hline P2. Uninterrupted operation & 5 & 1 & 2 & 0.582 \\
\hline P3. Low price & 3 & $1 / 2$ & 1 & 0.309 \\
\hline
\end{tabular}

Thus, the uninterrupted operation of heat supply is the most significant for consumers. Multiplying the received vector on the weight of consumers we find the importance of the purposes for the development of the heat supply system:

$$
0.186 \times\left(\begin{array}{l}
0.109 \\
0.582 \\
0.309
\end{array}\right)=\left(\begin{array}{c}
0.020 \\
0.108 \\
0.057
\end{array}\right) \quad \begin{gathered}
\text { compliance to the parameters } \\
\text { uninterrupted operation } \\
\text { low price }
\end{gathered}
$$

The results of similar calculations for other chosen actors (condominiums and authorities) are given in Tables \#6 and \#7.

Table 6. Determination of the purposes importance for condominiums

\begin{tabular}{|l|c|c|c|c|c|}
\hline & T1 & T2. & T3 & T4 & Priorities vector \\
\hline T1. Decrease in the accident rate & 1 & 2 & 3 & 3 & 0.453 \\
\hline $\begin{array}{l}\text { T2. Convenience of operation and } \\
\text { maintainability of the equipment }\end{array}$ & $1 / 2$ & 1 & 2 & 2 & 0.262 \\
\hline T3. Technology development & $1 / 3$ & $1 / 2$ & 1 & 2 & 0.167 \\
\hline T4. Profit & $1 / 3$ & $1 / 2$ & $1 / 2$ & 1 & 0.118 \\
\hline
\end{tabular}




$$
0.395 \times\left(\begin{array}{c}
0.453 \\
0.262 \\
0.167 \\
0.118
\end{array}\right)=\left(\begin{array}{c}
0.179 \\
0.103 \\
0.066 \\
0.047
\end{array}\right) \quad \begin{gathered}
\text { Decrease in the accident rate } \\
\text { Convenience of operation and maintainability } \\
\text { Technology development } \\
\text { Profit }
\end{gathered}
$$

Table 7. Determination of the purposes importance for the authorities

\begin{tabular}{|l|c|c|c|c|}
\hline & B1 & B2 & B3 & Priorities vector \\
\hline B1. Satisfaction of the population & 1 & 2 & 3 & 0.528 \\
\hline B2. Development of infrastructure & $1 / 2$ & 1 & 3 & 0.332 \\
\hline B3. Creation of new enterprises & $1 / 3$ & $1 / 3$ & 1 & 0.140 \\
\hline
\end{tabular}

$$
0.263 \times\left(\begin{array}{c}
0.528 \\
0.332 \\
0.140
\end{array}\right)=\left(\begin{array}{c}
0.139 \\
0.087 \\
0.037
\end{array}\right) \quad \begin{gathered}
\text { Satisfaction of the population } \\
\text { Development of infrastructure } \\
\text { New enterprises }
\end{gathered}
$$

Thus, the most significant purposes of the main actors are uninterrupted operation of heat supply for consumers, decrease in accident rate, convenience of operation and maintainability for TSO and satisfaction of the population for authorities. Using the received results, we receive total vector of the most significant purposes:

$$
\begin{aligned}
& \left(\begin{array}{l}
0,179 \\
0,139 \\
0,108 \\
0,103
\end{array}\right) \\
& \text { Convenience of operation and maintainability }
\end{aligned}
$$

After normalization it is finally received:

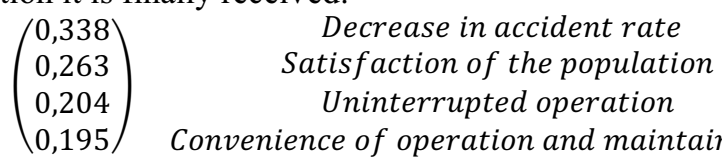

This vector will be used for receiving final scales of scenarios.

At the final stage the matrix "scenarios purposes" was formed. We define the weight of scenarios, concerning each of the final purposes of development. The calculation of the importance of scenarios is given in Table \#8.

Table 8. Influence of scenarios on the decrease in the accident rate

\begin{tabular}{|l|l|l|l|l|}
\hline & $\mathrm{C}$ & $\mathrm{D}$ & $\mathrm{E}$ & Priorities vector \\
\hline Centralization & 1 & $1 / 5$ & 2 & 0.179 \\
\hline Decentralization & 5 & 1 & 5 & 0.709 \\
\hline Electrical heat supply & $1 / 2$ & $1 / 5$ & 1 & 0.113 \\
\hline
\end{tabular}

Thus, the decentralized heat supply is the most perspective for the decrease in the accident rate. Similarly: - Satisfaction of the population $\left(\begin{array}{lll}0.179 & 0.751 & 0.070\end{array}\right)^{T}$;

- Uninterrupted operation (0.156 $0.659 \quad 0.185)^{T}$;

- Convenience of operation and maintainability $\left(\begin{array}{lll}0.188 & 0.731 & 0.081\end{array}\right)^{T}$.

The "scenarios purposes" matrix appears as:

$$
\left(\begin{array}{llll}
0.179 & 0.179 & 0.156 & 0.188 \\
0.709 & 0.751 & 0.659 & 0.731 \\
0.113 & 0.070 & 0.185 & 0.081
\end{array}\right)
$$

Multiplying the received matrix on the purposes vector, we find the total weight of basic scenarios in the combined scenario:

$$
\left(\begin{array}{cccc}
0.179 & 0.179 & 0.156 & 0.188 \\
0.709 & 0.751 & 0.659 & 0.731 \\
0.113 & 0.070 & 0.185 & 0.081
\end{array}\right) \times\left(\begin{array}{l}
0.338 \\
0.263 \\
0.204 \\
0.195
\end{array}\right)=\left(\begin{array}{l}
0.176 \\
0.714 \\
0.110
\end{array}\right)
$$

Thus, the perspective development of the heat supply system of Volgodonsk has to be performed mainly on the way of the development of the decentralized heat supply sources. 
The main advantage of the considered management instrument is its universality and flexibility. That allows to consider specific features of the specific territory of the country in strategic planning process. It is expedient to expand the circle of actors later, including scientific and technical organizations and producers of the equipment, considered in this work, as well as federal authorities (legislation) and investors. The specification of consumers by categories (population, industry, other consumers) is also possible. Besides, it is possible to detail basic scenarios and the purposes of certain actors within the more detailed research.

\section{Conclusion}

The scenario approach, allowing to consider and estimate possible options of achievement of effective objectives with the subsequent choice of the optimum taking into account the available external and internal restrictions according to system set criteria, is the integral part of strategic planning in the country. According to the authors the attempt of forming of the universal management instrument, which is interconnected with the development priorities, declared at the level of the state in the country and concrete situation of building in the certain territory significantly influencing the choice of the scenario of the development defining the options of construction and reconstruction of the facilities of heat supply is made. The development is performed on the example of Russia owing to the fact that there is considerable experience of development planning on the basis of "Schemes of heat supply of the territories" regulated at the level of the state standards, but at the same time they did not received due updating in the context of global environmental challenges including regarding the choice of scenarios of the development on alternative basis.

\section{References}

1. The energy strategy till 2035 in Russia [Digital resource] https://minenergo.gov.ru/node/18038,

2. Commission of the European Communities, European strategy of steady, competitive and safe power. Green Book (Brussels, 2006),

3. Energy strategy of Russia until 2030 [Digital resource] https://zen.yandex.ru/media/id/5efb9c988418ae604317191a/energeticheskaiastrategiia-rossii-na-period-do-2030-goda-5f7c19df40416f1e5b7bdc4a

4. Federal law No. 172-FZ "On strategic planning in the Russian Federation"(approved 28.06.2014) [Digital resource] http://docs.cntd.ru/document/420204138 (Access Mode: 02.02.2021)

5. Kostinboy A. S. Synthesis of experience of strategic planning of development of fuel and energy complex at the national level//Economic sciences, 135, 44-50 (2016)

6. International Energy Agency (IEA): Round table on the problems of the centralized heat supply in the conditions of transitional economy [Digital resource] https://www.rosteplo.ru/Tech_stat/stat_shablon.php?Id=497 (Access Mode: 05.02.2021).

7. On the requirements to the schemes of heat supply, order of their development and statement: Order of the Government of the Russian Federation (approved 22.02.2012) No. 154 [Digital resource] http://docs.cntd.ru/document/902332189 (Access Mode: 05.02.2021).

8. Verstina N, Tereshkina T. Evseev E 2018 Improvement of diagnostics and monitoring in the heat-supplying organizations in the complex of ecological management of urban 
development International Scientific Conference Enviromental Science for Construction Industry ESCI DOI:10.1051/matecconf/201819305038

9. Verstina N, Diagnostics of materials and structures of heating system as a component of ecological management in a modern city // MATEC Web of Conferences, Volume 73, article number 07022 (2016) Published online: 12 August 2016. DOI: 10.1051/matecconf/20167307022 (Web of Science)

10. Verstina N, Evseev E Technical-and-economic aspects of the analysis of the heating systems maintenance in the conditions of urban environment // MATEC Web of Conferences, 106, article number 08090 (2017) DOI: 10.1051/matecconf/201710608090

11. Saati T., Kearns To. Analytical planning. Organization of systems. Translated from English (Moscow, Radio and communication, 1991)

12. Tsuverkalova, O.F. Features of determination and selection of the factors influencing the choice of sites of capital repairs during implementation of the heat supply schemes. In book: Scientific progress as key factor of development of the sphere of knowledge. Collection of scientific works, pp. 130-136 (Kazan, 2020)

13. Gorbachev A.N. Enterprise management in the sphere of heat supply on the basis of stakeholder analysis, Work and social relations, 5, 147-158 (2016)

14. R. Dylewski, J. Adamczyk, Energy and Buildings 54, 88-95 (2012)

15. M. Tyre. RES POLICY 20-1, 57-76 (1991)

16. World power - 2050 (The White Book) [Digital resource], http://www.energystrategy.ru/editions/white_book2.htm

17. Energy Efficiency Trends in Buildings in the EU 2012. p 67 [Digital resource] Access Mode:

https://energiatalgud.ee/img_auth.php/6/68/Enerdata._Energy_Efficiency_Trends_in_ Buildings_in_the_EU._2012.pdf

18. Energy strategy of Russia until 2030, No. 1715-r (approved 13.11.2009) [Digital resource] https://www.garant.ru/products/ipo/prime/doc/96681/

19. A.A. Black, Terra Economicus, 9, 2, 2, (2011) [Google Scholar]

20. C.J. Kibert. Preface. In Proceeding of first International conference of CIB TG 16 on sustainable construction (Tampa, Florida, 1994) 